EOMmun Communication et organisation

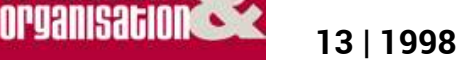

Management par projet et logiques

communicationnelles

\title{
Penser le multimédia
}

Hélène Dufau-Rossi

(2) OpenEdition

Journals

Édition électronique

URL : http://journals.openedition.org/communicationorganisation/2059

DOI : 10.4000/communicationorganisation.2059

ISSN : $1775-3546$

Éditeur

Presses universitaires de Bordeaux

Édition imprimée

Date de publication : 1 mai 1998

ISSN : 1168-5549

Référence électronique

Hélène Dufau-Rossi, «Penser le multimédia », Communication et organisation [En ligne], 13 | 1998, mis en ligne le 26 mars 2012, consulté le 19 avril 2019. URL : http://journals.openedition.org/

communicationorganisation/2059; DOI : 10.4000/communicationorganisation.2059

Ce document a été généré automatiquement le 19 avril 2019

(c) Presses universitaires de Bordeaux 


\title{
Penser le multimédia
}

\author{
Hélène Dufau-Rossi
}

DEGRÉS : Revue de synthèse à orientation sémiologique (Vingt-cinquième - vingt-sixième année. $n$ - 92-93 hiver 1997-printemps 1998 (182 p.) pag. multiple

2 Numéro coordonné par Pascal Lardellier; contributaires : Michel Melot, Emmaniel Pedler, Bernard Lamizet, Luc Massou, Isabelle Petit, Anne-Marie Christin, Jean Davallon, Pascal Sanson, Emmanuel Ethis, Roxane Bernier, Philippe Mabileau et Catherine Geoffroy, Richard Liogier

Dans cette livraison de « Degrés ", une douzaine d'auteurs de tous horizons tente, ainsi que le propose Pascal Lardellier, de "penser » le multimédia et «le " Réseau, en les examinant, selon la vocation de la revue, de points de vue divers.

4 On nous offre ainsi un concentré de réflexions stimulantes sur les recompositions des approches cognitives qu'induit le multimédia, en générant des synesthésies sensorielles, les sociabilités «fictives » des usagers du réseau, le questionnement méthaphysique dans le judaïsme, les potentialités offertes par le multimédia pour l'accès à la culture des handicapés (les aveugles plus précisément). Quels sont les modèles culturels sous-jacents au développement des produits et services, quelles structures de pensée et d'acquisition $\mathrm{du}$ savoir sont modifiées par leur usage; quelles modifications subissent les accès aux données et leur organisation, sont quelques unes des questions posées par les contributions de ce numéro.

5 Ce numéro dense, qui nous plonge au cœur des problématiques en gestation dans un domaine on ne peut plus actuel, sera d'une utilité certaine pour tous les chercheurs que préoccupent les dimensions sociales, culturelles, communicationnelles ou cognitives du multimédia. 